\title{
Research on the Effectiveness of Hybrid Teaching of General Mechanical Equipment Maintenance Course
}

\author{
Qingcai Liu \\ School of Mechanical and Electrical engineering, Guangzhou Railway Polytechnic, Guangzhou, China \\ Email: 807431278@qq.com
}

How to cite this paper: Liu, Q. C. (2021) Research on the Effectiveness of Hybrid Teaching of General Mechanical Equipment Maintenance Course. Journal of Service Science and Management, 14, 627-635. https://doi.org/10.4236/jssm.2021.146039

Received: November 30, 2021

Accepted: December 21, 2021

Published: December 24, 2021

Copyright $\odot 2021$ by author(s) and Scientific Research Publishing Inc. This work is licensed under the Creative Commons Attribution International License (CC BY 4.0).

http://creativecommons.org/licenses/by/4.0/

\section{(c) (i) Open Access}

\begin{abstract}
Based on practice of hybrid teaching in the course of general mechanical equipment maintenance, this paper studied factors affecting the effectiveness of traditional teaching and hybrid teaching. It was considered that the effectiveness of teaching was affected by many factors, and traditional curriculum teaching was affected by orientation of curriculum objectives, students' learning enthusiasm, teachers' teaching ability, teaching methods and teaching software and hardware resources. In addition to above factors, hybrid teaching was also affected by construction quality of MOOC or SPOC and related application ability. With hybrid teaching of general mechanical equipment maintenance, the average scores of teaching classes were significantly improved. The improvement range of hybrid teaching was $8.1 \%-26.3 \%$. The results of students who were enrolled from secondary vocational schools were improved by $8.1 \%-15.3 \%$ after adopting hybrid teaching. The scores of students enrolled in the college entrance examination increased by $13.1 \%-26.3 \%$.
\end{abstract}

\section{Keywords}

Traditional Teaching, Course, Hybrid Teaching, Teaching Effectiveness, Evaluation

\section{Introduction}

After completing teaching of a course, teachers generally hope that the course has effective value to students. The value mentioned here is the value of the course itself, and the other is that students get all or part of the value through teaching activities, so as to provide help for their future learning, employment and even career development. The latter involves the problem of effective teach- 
ing. Effective teaching means that teaching can effectively promote students' development and effectively achieve the expected teaching objectives (Liu, 2008). That is, under the condition of meeting goals of the times and individual values, its efficiency is not lower than the average level in a certain time and space (Liu, 2011). The effectiveness of teaching does not entirely depend on whether teachers have finished contents of a teaching plan or whether they are serious in teaching within a specified time, but whether students have learned anything from teaching, whether students have learned well, or whether students can skillfully and creatively apply knowledge.

Because vocational education puts more emphasis on the problem of ability transmission, but ability and knowledge have an inseparable relationship. Ability is the external expression of knowledge, and the essence of ability transmission is also knowledge transmission. The main content of effective teaching research is how to impart effective knowledge to students. Research on the effectiveness of teaching and effective teaching is helpful to achieve the goal of talent training. After higher vocational education enters the stage of connotation construction, it is natural to pay more attention to teaching problems at the micro level, strengthen research, supervision, inspection and guidance of teaching effectiveness, and promote the improvement of teaching quality.

With development of mobile internet technology, online courses have become a new method and means to change traditional classroom teaching and learning. Many teachers applied MOOC or SPOC to daily teaching and carried out hybrid teaching and research. Some researchers discussed importance of research on the effective strategy of English classroom teaching in polytechnics under information environment, pointed out the specific existing problems, and put forward the effectiveness strategy, in order to provide reference for the improvement of English teaching and the cultivation of comprehensive talents (Zhang, 2021). Some researchers put forward a hybrid teaching mode based on SPOC platform in view of some shortcomings in the teaching of fundamentals of basic information system engineering. Through the construction of hybrid teaching mode, the design of teaching mode and the implementation of more perfect assessment and evaluation mechanism, the classroom teaching process was improved, which reflected the teaching strategy of student-centered and students' active learning. This mode maximized the use of classroom time and improves the teaching effect (Zhang, Ma, Wei, \& Zhang, 2021). Some researchers also discussed how to implement hybrid teaching research and practice in the course of electrotechnics and electronics, explored the hybrid teaching mode, method and content suitable for the course, built a hybrid teaching network platform for comprehensive management and service of mobile teaching, and promoted its application in the whole school (Zhi \& Yang, 2019).

Because higher vocational education is employment oriented education, it has opened a variety of courses. Different courses have different characteristics and need different teaching methods. All kinds of general machinery and equipment are widely equipped in the railway and subway industry. Equipment mainten- 
ance requires a large number of personnel. It is necessary to carry out relevant teaching research, especially the research on the effectiveness of hybrid teaching. In addition to the author's research on MOOC construction and hybrid teaching of general mechanical equipment maintenance course (Liu \& Wan, 2021a, 2021b), from the perspective of literature retrieval, there is a lack of teaching research on general mechanical equipment maintenance in railway and subway industry, and it is even more difficult to see the evaluation research on the effectiveness of hybrid teaching of the course.

Hybrid teaching cannot be completely separated from traditional teaching. The factors affecting the effectiveness of teaching in traditional teaching will generally affect hybrid teaching. Therefore, on the basis of discussing the effectiveness of traditional teaching, this paper discussed the factors affecting hybrid teaching. In order to illustrate the influence of hybrid teaching, taking the course of general mechanical equipment maintenance as an example, this paper analyzed the students' scores since the author engaged in the teaching of this course. Through the changes of students' average scores in traditional teaching and hybrid teaching, this paper quantitatively explained the impact of hybrid teaching on students' scores.

\section{Reasons Affecting the Effectiveness of Traditional Teaching and Hybrid Teaching}

\subsection{Reasons Affecting the Effectiveness of Traditional Teaching}

1) Inaccurate positioning of course objectives

Higher vocational education is mainly employment oriented education (Liu, 2011). The setting and teaching of various majors and courses shall have distinct professional pertinence. Students shall be able to master knowledge and skills closely related to job posts through learning. When the orientation of curriculum objectives is not accurate, there are problems in the basis of curriculum effectiveness. In this case, no matter how hard teachers teach and how hard students study, it is difficult to achieve the expected teaching effect.

2) Insufficient students' learning enthusiasm

With the popularization of higher education, the enrollment scores of higher vocational students have been gradually reduced, the sources of students are diversified, and the overall knowledge literacy has been reduced (Liu, 2011). Students tend to have no solid grasp of basic knowledge, resulting in low abstract thinking ability and great learning difficulties. Students' learning confidence and interest are also insufficient, making it more difficult to accurately master knowledge and skills. A considerable number of students' career planning is not clear, their learning purpose is not clear too. They have not formed good learning habits. Students generally have the following shortcomings: lack of concentration in class, improper learning attitude, lack of learning initiative and enthusiasm. Therefore, the learning effect cannot be good.

3) Insufficient teachers' theoretical and practical ability 
For higher vocational education, teachers are required to be familiar with the whole knowledge and skills of a course, have rich teaching experience and be good at controlling classroom situation (Wang, 2021). Teachers shall have a strong sense of responsibility, fully prepare lessons, and carefully carry out teaching planning and design. Teachers shall master the actual situation of relevant posts in a course, and their teaching shall be close to actual situation as much as possible, so as to stimulate students' interest in learning. In teaching design, teachers shall be able to adopt different methods according to characteristics and requirements of different knowledge points, and make appropriate use of various resources to make teaching easy to understand.

4) Improper implementation of teaching

In order to adapt to change of talent training requirements, teaching of higher vocational education has changed from pursuit of knowledge system to sufficiency of theory, and vocational post skills have changed from narrow practical training to cultivation of comprehensive vocational ability (Liu, 2008). At the same time, in order to improve teaching quality, higher vocational teaching methods have also been constantly changing. But in a specific implementation process, restricted by various circumstances, teaching methods are often unreasonable or improperly implemented, unable to carry out effective teaching. That affects final effect. For example, the teaching of equipment structure principle is lack of animation or video, lack of equipment, improper to organize practical teaching, insufficient practice after theoretical calculation explanation, insufficient discussion on fault diagnosis and troubleshooting methods. For simple and easy knowledge, because students don't like self-study, classroom explanation takes up too much time.

5) Insufficient teaching software and hardware resources

For the teaching of mechanical equipment, only one textbook is far from meeting requirements of effective teaching. In order to achieve ideal teaching effect, we need not only software resources such as pictures, principle animation and video, but also hardware resources such as models, equipment, tools and measuring tools (Wang, 2021). If there are conditions, it is more popular for students to go to enterprise to observe corresponding equipment.

There are many factors affecting teaching, and the above are only typical factors affecting traditional teaching. Other factors sometimes have an adverse impact. For example, under the background of generalization of teaching reform, talent training plan changes frequently, and major's leaders do not know enough about each course, resulting in unreasonable course hours. Insufficient class hours cannot achieve expected objectives, and excess class hours will cause waste.

\subsection{Reasons Affecting the Effectiveness of Hybrid Teaching}

In addition to above factors, the use of MOOC or SPOC in hybrid teaching is also affected by following factors according to the author's experience.

1) Quality of MOOC or SPOC 
The quality of online courses has a direct impact on the effect of hybrid teaching. A good course shall arrange learning resources in a project-oriented way as far as possible. Each project contains several learning tasks, and each task includes learning resources for several knowledge and skill points. A good MOOC or SPOC shall have rich resources. Resources shall include video, text corresponding to teaching video, principle animation or practice video, exercises directly related to each learning task, project test, online examination, etc.

2) Reasonable use of MOOC or SPOC

MOOC or SPOC needs to be used reasonably in order to maximize teaching benefits. Through division of pre class, in class and after class, as well as reasonable arrangement of learning tasks and teaching activities, on the one hand, it expands classroom space and time and makes full use of the after class time; on the other hand, it embodies the concept of learner centered, allowing students to control the learning process independently and give full play to students' initiative. Through students' after-school learning, they have questions about learning difficulties, which are often teaching difficulties. By implementing hybrid teaching, classroom teaching can reduce relatively simple content explanation and make teachers focus more on teaching difficulties. Through adequate explanation, discussion, classroom practice, practical training and other appropriate ways, hybrid teaching can overcome difficulties and deepen students' cognition.

\section{Effectiveness Evaluation of Hybrid Teaching of General Mechanical Equipment Maintenance Course}

\subsection{Analysis on General Mechanical Equipment Maintenance Course}

The course of general mechanical equipment maintenance has been opened for more than 10 years. After gradual evolution and development, its content and teaching objectives have become more and more clear and reasonable. The course requires to master structure, principle, use and adjustment methods, typical faults and troubleshooting of crown, water pump, fan and piston compressor. The course was equipped with specially customized training equipment such as double beam crown, water pump, centrifugal fan and piston air compressor. Its teaching hardware can support on-site teaching, equipment operation, action demonstration, disassembly and commissioning of key structures and other teaching activities. The situation of these teaching activities is more specific, easy to attract students' attention and stimulate their interest in learning, which plays an important role in improving teaching efficiency.

In terms of teachers' quality, the course lecturer worked in enterprises for many years, who is familiar with application and maintenance of equipment and has a solid theoretical foundation because of experience of systematic doctoral study and training in scientific research institutions. Moreover, after more than ten years of teaching research, the lecturer has rich teaching experience. In terms of software, the course has collected rich video, animation and picture resources, and established an online course based on campus platform. Comprehensively, 
without considering the influence of school running mode, the course of general mechanical equipment maintenance is already at an ideal level from the perspective of traditional teaching. However, only being satisfied with traditional teaching methods cannot meet requirements of the development of the times. The problems existing in traditional teaching, such as bad control of learning process, insufficient homework practice, untimely feedback and incentive, still exist in varying degrees and cannot be completely overcome.

\subsection{Implementation and Evaluation of Hybrid Teaching of General Mechanical Equipment Maintenance}

From the perspective of course construction quality, the course of general mechanical equipment maintenance divided learning projects around structure, principle, use and regulation methods, typical faults and troubleshooting of crown, water pump, fan and compressor. Each project was divided into several tasks according to the internal relationship of knowledge, realizing the action oriented course design. At the same time, it realized granulation and fragmentation of knowledge and skills (Liu \& Wan, 2021a). Granular and fragmented knowledge points can reduce the difficulty of learning and facilitate the use of spare time after class to learn at any time. MOOC and SPOC have video and text resources corresponding to each knowledge particle. Animation and video resources were equipped for difficulties about principle structure. Each task was equipped with homework. After learning a project, students must take a test. After the whole course is completed, students must complete the course examination (Liu \& Wan, 2021b). Compared with traditional courses, although the amount of exercise has increased dozens of times, the platform has the function of performance evaluation, and the burden of teachers' marking homework does not increase in the same proportion. It embodies the advantage of "being able to learn and assist in teaching".

Deepening learning effect is the goal of each course, and stimulating learning interest is the premise to achieve good effect. Interest is the best teacher. Through teaching practice, teachers can know that practical teaching is the best way to attract students' attention and stimulate their interest in learning. Due to the limitation of class hours, traditional curriculum teaching often cannot arrange enough time for in class training. By adopting hybrid teaching, students are arranged to self-study MOOC or SPOC before class for less difficult general knowledge, so as to save time for in class practical training, or carry out more on-site teaching according to the content of learning tasks. That can deepen students' understanding of equipment and obtain more effective teaching. After class, students complete homework and tests on MOOC or SPOC. SPOC platform can monitor the completion of each student's tasks before and after class.

Free discussion can deepen students' understanding of relevant knowledge and cultivate students' divergent thinking. Due to the influence of traditional habits, students often avoid speaking or asking questions, and it is difficult to discuss too much in class due to time limit. The constructed MOOC and SPOC 
courses were provided with 40 free discussion topics, so that students can freely express their views after learning relevant knowledge particles. Right and wrong answers are not used as evaluation criteria. The benefit of doing so is to inspire students' thinking as much as possible and get rid of the shackles of rote learning habits.

In order to quantitatively evaluate the learning effect of hybrid teaching, the relevant data were given in Table 1 below. The data in the table is the average score of general mechanical equipment maintenance course from different years, classes and students enrollment. All data was from the author's practical teaching.

It can be seen from the data in Table 1 that the average score of classes with hybrid teaching is significantly higher than that of classes without hybrid teaching. Taking traditional teaching max or min score as the base, by selecting the lowest average score and the highest average score of traditional teaching class respectively, and then selecting the lowest score and the highest score of the hybrid teaching class, it can be calculated that the improvement range of hybrid teaching score is $8.1 \%$ - $26.3 \%$. This shows that the effectiveness of hybrid teaching is significantly higher than that of traditional teaching. The transition

Table 1. Comparison of scores before and after hybrid teaching.

\begin{tabular}{|c|c|c|c|c|c|c|}
\hline & Year & $\begin{array}{c}\text { Class } \\
\text { No. }\end{array}$ & $\begin{array}{c}\text { Average } \\
\text { score }\end{array}$ & $\begin{array}{c}\text { Max/min } \\
\text { score }\end{array}$ & $\begin{array}{c}\text { Max/min percent } \\
\text { of improvement } \\
(\%)^{3}\end{array}$ & $\begin{array}{c}\text { Enrollment } \\
\text { type }\end{array}$ \\
\hline \multirow{5}{*}{$\begin{array}{l}\text { Hybrid } \\
\text { teaching }\end{array}$} & \multirow{2}{*}{2021} & 1 & 79.5 & \multirow{5}{*}{$\begin{array}{c}81.6 / 78.3 \\
81.4 / 79.5^{(1)} \\
81.6 / 78.3^{(2)}\end{array}$} & \multirow{5}{*}{$\begin{array}{c}26.3 \% / 8.1 \% \\
26 \% / 13.1{ }^{(1)} \\
15.3 \% / 8.1 \%{ }^{(2)}\end{array}$} & (1) \\
\hline & & 2 & 81.5 & & & (2) \\
\hline & 2020 & 1 & 81.4 & & & (1) \\
\hline & \multirow{2}{*}{2019} & 1 & 81.6 & & & (2) \\
\hline & & 2 & 78.3 & & & (2) \\
\hline \multirow{2}{*}{$\begin{array}{c}\text { Transition } \\
\text { stage }\end{array}$} & \multirow{2}{*}{2018} & 1 & 75.7 & \multirow{2}{*}{$75.7 / 73.7$} & \multirow{2}{*}{$17.2 \% / 1.8 \%$} & (1) \\
\hline & & 2 & & & & (1) \\
\hline \multirow{5}{*}{$\begin{array}{c}\text { Traditional } \\
\text { teaching }\end{array}$} & 2017 & 1 & 67.3 & \multirow{5}{*}{$\begin{array}{c}72.4 / 64.6 \\
70.3 / 64.6^{(1)} \\
72.4 / 70.8^{(2)}\end{array}$} & - & (1) \\
\hline & & 1 & 72.4 & & \multirow[b]{2}{*}{ - } & (2) \\
\hline & 2016 & 2 & 64.6 & & & (1) \\
\hline & 2015 & 1 & 70.3 & & - & (1) \\
\hline & 2014 & 1 & 70.8 & & - & (2) \\
\hline
\end{tabular}

Note: (1) By higher education entrance examination or from high school. (2) From technical secondary school. (3) Max percent of improvement (\%) = (Max score of hybrid teaching-min score of traditional teaching)/min score of traditional teaching. Min percent of improvement $(\%)=$ (Min score of hybrid teaching-max score of traditional teaching)/max score of traditional teaching. The calculation for transition stage is similar with above. 
stage in Table 1 is the initial stage of trying to adopt hybrid teaching. Compared with traditional teaching, the performance in the transition stage was improved, and the maximum increase can be calculated as $1.8 \%-17.2 \%$. However, it is significantly lower than the performance of the formal implementation of hybrid teaching stage. This proved that the rational and effective use of MOOC and SPOC has a significant impact on the effectiveness of teaching.

From comparison of enrollment types, with similar calculation, the scores of students from secondary vocational schools after hybrid teaching were also significantly improved, with an increase range of $8.1 \%-15.3 \%$. The scores of students enrolled by national college entrance examination from high school increased by $13.1 \%-26.3 \%$. The performance improvement of the latter after adopting hybrid teaching is greater than that of the former. The author believes that this may be due to two reasons: one is the lack of learning motivation of students enrolled in the college entrance examination under traditional teaching mode. Second, students enrolled in the college entrance examination have stronger learning ability. Under the constraints of MOOC or SPOC, they have greater potential to improve their performance. Whether hybrid teaching was adopted or not, we can see that there were differences in the scores of different classes, which may reflect the impact of class atmosphere and study style on the scores of different classes.

\section{Existing Deficiencies and Recommendations}

Using MOOC or SPOC to carry out hybrid teaching in the course of general mechanical equipment maintenance can indeed improve students' performance and improve the effectiveness of teaching. However, as a teaching method to meet the requirements of development of the times, there is still a lot of work to be further improved. First, we need to continue to optimize curriculum structure in an action oriented way. The second is how to efficiently and reasonably build curriculum resources, that is, how to use video, animation and other ways to show curriculum content at a reasonable cost to reduce learning difficulties.

Despite the establishment of MOOC or SPOC, the construction of training resources of the course cannot be relaxed. The construction of training resources should be based on the principle of modularization and organized according to knowledge and skill points to facilitate teaching. Teachers should fully master the operation and use of training equipment, reasonably organize the training process, and give full play to the advantages of training to deepen and master knowledge and skills and stimulate students' interest in learning.

Teaching evaluation shall also keep pace with the times, take whether to carry out hybrid teaching as an important observation point of teaching effectiveness, and promote the construction and application of curriculum informatization.

\section{Conclusion}

The effectiveness of teaching is affected by many factors. The traditional curri- 
culum teaching is affected by the orientation of curriculum objectives, students' learning enthusiasm, teachers' teaching ability, teaching methods and teaching software and hardware resources. In addition to the above factors, hybrid teaching is also affected by the construction quality of MOOC or SPOC and the application level of MOOC or SPOC.

After hybrid teaching of general mechanical equipment maintenance course, the average scores of classes have been significantly improved. The improvement range of hybrid teaching is $8.1 \%-26.3 \%$. The results of students from secondary vocational schools were improved by $8.1 \%-15.3 \%$ after adopting hybrid teaching. The scores of students enrolled in the college entrance examination increased by $13.1 \%-26.3 \%$.

\section{Acknowledgements}

This article was funded by the 2019 teaching and scientific research project of Guangzhou Railway Polytechnic (Document No [2019] 12)

\section{Conflicts of Interest}

The author declares no conflicts of interest regarding the publication of this paper.

\section{References}

Liu, Y. J. (2008). Teachers Shall Consider "Effective Teaching” in Teaching. Journal of Cheng Du University of TCM (Educational Science Edition), 10, 23-24.

Liu, G. Q. (2011). Research on Promoting Effective Teaching in Higher Vocational Education. Scientific and Technological Information, 230-231.

Zhang, K. (2021). The Research on the Effective Strategies of English Classroom Teaching in Higher Vocational Colleges in the IT Environment. Journal of Xingtai Polytechnic College, 38, 14-18.

Zhang, T., Ma, P. F., Wei, W. B., \& Zhang, J. L. (2021). Exploration and Practice of Hybrid Teaching Mode Based on SPOC Platform. China Plant Engineering, 10, 213-214.

Zhi, Y., \& Yang, G. H. (2019). Research and Practice of Hybrid Teaching in the Course of Electrical Engineering and Electronics. Open Access Library Journal, 6, e5890.

Liu, Q. C., \& Wan, X. C. (2021a). MOOC Construction of General Machinery Equipment Maintenance. Open Journal of Social Sciences, 9, 147-155.

https://doi.org/10.4236/jss.2021.93009

Liu, Q. C., \& Wan, X. C. (2021b). Practical Research on the Application Characteristics and Countermeasures of Online Course Based on MOOC. Open Journal of Social Sciences, 9, 67-74. https://doi.org/10.4236/jss.2021.911006

Wang, C. Y. (2021). Analysis of Effective Factors and Countermeasures of Classroom Teaching in Vocational Education Based on the Reform of "Three Education". Modern Vocational Education, 42-43 